


\title{
Ronda: nuevas noticias sobre el primer y antiguo puente del Tajo
}

\author{
Inocencio Cadiñanos Bardeci
}

Sobre este bello y famoso puente ya se ha escrito su proceso de construcción. Sin embargo, al hablar del primer intento de levantarlo, se exponen unas muy breves noticias que pretendo completar con otras halladas recientemente'.

Cuando a comienzos del siglo XVIII las autoridades locales insisten en la necesidad de construir el nuevo puente, recuerdan el muy especial emplazamiento de la ciudad y su barrio del Mercadillo "siendo su situación en sitio eminente, estrecho, rodeada de el taxo escarpado que le sirve de muro [...] luego de la conquista se ensanchó formando otra población más numerosa en terreno menos fragoso hasta aver ocupado la llanura grande nombrada de Mercadillo, igual su altura a la del casco de la ciudad y separándolas dos taxos que forman foso profundo». Resultaba incómoda su comunicación puesto que solo era accesible «por una rampa artificial al medio día que la comunica con el barrio de San Francisco que se compone de 500 vecinos. Al norte está el barrio de Mercadillo de 3.000 vecinos sobre el borde de la otra. El tajo tiene de distancia 28 varas por unos sitios y 42 por otro». Dicha rampa era «muy pendiente y trabajosa [...] de tal modo que se reputa (el barrio) por una porción distinta de esta ciudad». Los tajos resultaban tan abruptos que no distando entre sí más de 30 varas se necesitaba cerca de media hora de camino para llegar a la otra margen. A levante estaba el arruinado arrabal de San Miguel con un destrozado puentecillo que servía de paso del río Guadalevín. Era conocido como «romano», con un pequeño arco de medio punto, incapaz de acoger las aguas crecidas del cauce. El otro paso, más cercano al pueblo, salvaba el río en la parte baja del Tajo.

Sabemos que, tras la conquista de Ronda por los RR. CC., aumenta rápidamente la población del barrio de Mercadillo al no poder ampliarse la vieja ciudad circundada de murallas. El barrio es agraciado con un mercado franco en 1488, libre de las imposiciones municipales. Ante su prosperidad, al año siguiente es levantado el segundo y más importante de los citados puentes (entonces llamado

1 CAMACHO, Rosario, y MIRÓ, Aurora "Antecedentes del Puente Nuevo de Ronda", Academia. Boletín de la Real Academia de Bellas Artes de San Fernando, n. ${ }^{\circ} 79$, Madrid, 1994, pp. 291-314. 
"Nuevo" y después "Viejo») por los canteros vizcaínos Sancho de Endeiza, Juan Pérez de Endeiza y García de Urtubiega ${ }^{2}$ que, a comienzos del siglo XVI, será protegido y controlado por una puerta fortificada, sin duda con finalidad fiscal.

El nuevo puente que aquí estudiamos, proyectado en los siglos XVII y XVIII capaz para todo carruaje, solucionaría tales inconvenientes además de conseguir formar una sola población.

\section{La petición municipal de la construcción del puente}

El puente actual sobre el Tajo, tan Ilamativo, fotogénico y elogiado por la literatura, es obra trabajosa y costosa del siglo XVIII. A pesar de la evidente necesidad y urgencia para relacionar ambas poblaciones, el mal comienzo y continuas dudas sobre su más acertado emplazamiento, sólida construcción y fracasos, alargarían las obras durante casi todo el siglo.

Todo ello «hizo que mui luego se pensara en hazer un puente en el sitio más proporcionado de los taxos con el que la población queda con llanura y la entrada fácil a todo tráfico. Pero no pudo tener efecto en el pasado por las epidemias grandes que padeció el pueblo y falta de fondos en sus propios. A mitad del siglo pasado (el XVII) se fixaron considerables sumas para esta obra. Se formaron planos pero no tuvo efecto hasta inicios de este siglo". Efectivamente, las autoridades municipales habían solicitado construirle en 1692. Eran malos tiempos y el permiso no llegó hasta unos cuantos años más tarde.

En 1701 tenemos constancia de una nueva consulta hecha por las autoridades locales exponiendo ante el Consejo «que su situación estaba sobre el río Tajo que la circundaba y que para pasar al barrio que Ilamaban del Mercadillo tenía grandísimo rodeo por lo áspero de los sitios con pérdida de la salud y manquedad de las caballerías, por cuio motivo había acordado hacer un puente para unirle con dicha ciudad». Pedían facultad para usar de ciertos arbitrios. Al año siguiente volvían a recordar la necesidad del puente y que «se le había concedido licencia y facultad [en el pasado] para fabricar un puente en el Tajo de Santo Domingo al varrio que llaman de Mercadillo por la grande utilidad y precisión que de su conservación [sic] havía». Para ello fueron señalados diferentes arbitrios durante 4 años entre ellos el $1 \%$ de las carnes, el $3 \%$ de las mercaderías que se vendieran en la feria de mayo y el arrendamiento de las tierras de la fuente de la

2 Simancas: RGS, t. VI, 289 (26 enero 1489). 
Arena. Era urgente emprender la construcción «por obiar muchas fatalidades y delitos que se cometían con el motivo de no poder la justicia acudir prontamente a su remedio y a la aprehensión de los delincuentes»»3.

\section{El alarife Francisco Gutiérrez y su actuación en Ronda}

\section{Intervención en la colegiata}

La actuación del granadino Francisco Gutiérrez Sanguino en la colegiata venía de bastantes años antes del contrato del puente sobre el Tajo. Efectivamente, en 1681 informaba el cabildo que se estaba tratando de reedificarla por hallarse arruinada. Los beneficiados tenían que ir a decir misa al Espíritu Santo. La economía de la ciudad se había agravado con los golpes de la peste. No existían medios para llevarlo a cabo. Solicitaba del rey, patrono del templo, que señalara algunos arbitrios para ello. Podrían ser una parte de los diezmos.

En 1684 se decía que "habiéndose fenecido el cuerpo de la iglesia [...] se pasó a discurrir se prosiguiese al fenecimiento de la ynsigne quanto pulida obra de la capilla mayor con los dichos arbitrios». Se sacó a pregón y fue rematado en Gutiérrez, incluidas puertas y ventanas, pero con excepción de la solería de la capilla mayor, por 7.700 ducados. Se trataba, sobre todo, de la armadura y tejado. Acabada la obra, hizo vicio en uno de sus ángulos. Entregó la ciudad mucho dinero y habiendo notado varias deficiencias, nombró para informar al maestro mayor de Sevilla, Blas Sancho, quien declaró errada y mal obrada la cubierta. Hubo pleito en 1713. Gutiérrez se negó a pagar los 58.000 rs. del reparo. Se le embargaron los bienes y se le apresó junto a sus oficiales Alonso Gago y Diego Romero.

Al año siguiente volvían a examinarlo otros maestros. La armadura de la capilla mayor estaba mal fabricada y debía ser reconstruida por entero, según declaró Lorenzo Fernández Iglesias, maestro mayor de Sevilla. Era necesario rebajar la media naranja y tender, en su lugar, una bóveda de crucería de ladrillo además de mejorar varios detalles en hornacinas, ventanas y solado. Costaría 3.000 ducados. También lo reconocieron Felipe Unzurrunzaga, maestro mayor de la catedral de Málaga, y Leonardo de Figueroa, de la de Sevilla. Dijeron que estaba ejecutada contra arte toda la armadura y con principios de ruina. Según

3 AHN, Cons. legs. 2.695, 5.919 y 12.669. 
el proyecto y aclaraciones de estos últimos maestros, Gutiérrez se comprometió a perfeccionarla por $7.000 \mathrm{rs}$.

El templo actual presenta un aspecto bastante diferente al que nos remiten las noticias anteriores ${ }^{4}$.

Simultáneamente a la armadura y tejado, el solado del templo fue encargado a Francisco del Castillo. Si fuera de jaspe costaría 42.000 rs., si de piedra, 33.000. Se le adjudicó por 40.493 rs. Recibió 29.655 rs, murió sin finalizarlo y sus herederos y fiadores no respondieron de la conclusión. Fue apreciado lo hecho en 20.324 rs. Después continuó el tendido de la solería por los maestros Esteban de Salas y José de Otero en quienes se remató por 38.953 rs. En las cuentas de comienzos del siglo se mencionan 65.807 rs. "gastados en la solería de la iglesia mayor". Pero tampoco lo acabaron.

En el año 1700 el mencionado Francisco Gutiérrez firmó la escritura de la conclusión del solado de la iglesia. Quedaban excluidos el presbiterio y espacio de los púlpitos. Se comprometió a tenerlo acabado en dos años, se le abonaron varias partidas, pero pasaron seis años y no puso ni una losa sin dar cuenta del dinero. En 1707 "ganó esta ciudad facultad de S. M. para arbitrar sobre diferentes efectos a que está contribuyendo hasta el más pobre" señalándose en ellos 4.000 ducados para la solería de la iglesia mayor y 12.000 para acabar el puente. Se le exigió a Gutiérrez que comenzase los trabajos de la solería, junto con otras obras contratadas.

Sin embargo, la conclusión se debió a Felipe de Unzurrunzaga a juzgar por cierto documento de compromiso fechado en 1716 en que se estaba "procediendo al fenecimiento de la obra de solería y presbiterio de jaspe de la capilla mayor, hornacinas y valla de la iglesia mayor de dicha ciudad de Ronda». Se obligó a ejecutarlo por 37.000 rs. pues era mucha la obra que habían dejado de hacer los anteriores maestros ${ }^{5}$.

\section{Remate y suspensión de las obras del nuevo puente sobre el Tajo}

En el arriba citado momento del remate de las obras de la colegiata se informó, también, a los maestros presentes que el coste del puente era de 20.000 ducados.

4 AA.VV. Catálogo artístico de Málaga y su provincia, vol. 2, Madrid, 1985, pp. 271-276. CAMACHO MARTÍNEZ, Rosario, Málaga Barroca. Arquitectura religiosa de los siglos XVII y XVIII, Málaga, Arguval, 1981, pp. 417-421.

5 LLORDEN, A., Arquitectos y canteros malagueños, Ávila, 1962, pp. 129-133. 
La documentación de 1701 da a entender, aunque no lo dice expresamente, que el proyecto y condiciones se debieron a Gutiérrez. Las autoridades locales le agregaron alguna otra cláusula como que se colocaría a la entrada de Mercadillo una portada de cantería donde se pondrían los escudos de la ciudad. Al contratista se le facilitaría el poder cortar toda la madera necesaria pagando su importe. Se le garantizaría el traspaso de cuatro solares junto a las entradas, necesarios para agrandar ingresos y salidas. El puente debería estar acabado en dos años.

Fue adjudicado a Gutiérrez el 3 de mayo de 1702. Principió la fábrica al año siguiente y se gastaron en ella más de 8.000 ducados. Pero pronto cesó y «no ha llegado el caso de su construcción por haberse aplicado el producto de dichos arbitrios para otros fines y urgencias tocantes al real servicio".

Por real cédula de 16 octubre de 1707 los arbitrios fueron prorrogados por 8 años con el fin de concluir y perfeccionar el puente nuevo. Lo que faltaba por hacer había sido estimado en 12.000 ducados y en 4.800 rs. el valor de los citados cuatro solares precisos para despejar las entradas y salidas. Cuando en este mismo año viene el arriba mencionado Blas Sancho a reconocer los trabajos de la colegiata, también examinó lo ejecutado en el puente. Declaró que «los pilares y demás obra en ella iban de buena materia, pero había hallado haber faltado maestro inteligente en el modo de la execución" aconsejando a la ciudad que trajese alguien de conocimiento y práctica que asistiese a la obra según arte pues la magnitud de la construcción así lo requería. Apreció lo hecho por Gutiérrez en 47.366 rs. y los materiales y pertrechos en 18.000 .

Dicho informe dejaba claro que también en el puente se estaba trabajando deficientemente. Las autoridades denunciaron que el contratista "por lucrarse en mayor porción llevó la obra con tan poca firmeza que fue denunciada y mandada deshacer». Quedó alcanzado en 13.966 rs. y se ordenó apresarle, pero huyó.

A pesar de la necesidad y urgencia por disponer del paso, la obra quedó en suspenso durante más de dos décadas. Las cuentas municipales nos hablan de otros trabajos y destinos de los ingresos municipales: un puente en la Dehesa, empedrado de las calles, acondicionamiento de la fuente y cañería de Mercadillo y contribución a las guerras de Felipe V. En estas circunstancias, los recursos para proseguir con el nuevo puente fueron nulos lo que explica su olvido durante mucho tiempo. 


\section{La continuación por Juan Antonio Camacho}

En 1733 se intentaba reanudar los trabajos. A principios del año siguiente "habiéndose sacado a pregón la obra se había hecho postura por don Juan Camacho Saavedra, maestro mayor de obras del reyno de Córdoba y de su catedral» en la cantidad en que antes había sido rematado rebajándose 8.000 ducados por lo que estaba fabricado quedando en 12.000 . No entraban los solares señalados en 1707. El nuevo plan también se debía a Camacho.

La postura era mejor que la anterior pues Gutiérrez solo se había obligado a darle 7 varas de anchura y ahora era ampliado a 8 "para su mayor permanencia, desahogo, decencia y utilidad». En 1736 presentó las escrituras de obligación y fianza. Entre las condiciones estaba el que la ciudad le entregaría la cuarta parte de los 12.000 ducados y el importe de los 4 solares que ascendía a 137.800 rs. Las $3 / 4$ partes restantes se le pagarían de 6 en 6 meses $^{6}$. La obra iba sobre lo levantado por Gutiérrez con poca o ninguna modificación o prevención para mejorar sus bases o apoyos anteriores denunciados como inseguros, lo que acarrearía su ruina.

\section{Arbitrios, inversiones y cuentas}

Como se ha dicho, en sus comienzos la obra fue rematada en Gutiérrez en 20.000 ducados. Fueron señalados arbitrios por valor de 2.000 ducados anuales que, después, se desviaron hacia diversas urgencias nacionales y municipales lo que ralentizó los trabajos.

Se concedieron repetidas facultades desde 1702 hasta 1725 para usar los arbitrios del $1 \%$ en las carnes, $3 \%$ de las mercancías foráneas llegadas a la feria de mayo y arriendo de las tierras del prado de la Arena y parte de la dehesa de la Sanguijuela. Fueron aprobadas las cuentas presentadas hasta fines de 1721 y se solicitó la prórroga de los anteriores arbitrios por otros 10 años, pero se accedió a sólo 6 años. Volverían a ser prorrogados posteriormente "todo lo cual había de servir para concluir la construcción de dicho puente». Sin embargo, el 2 de julio de 1728 se ordenó cesar en ellos.

6 AHN, Cons. leg. 4001. Expediente formado a representación de Dn. Francisco Basco y Rivero, regidor de la ciudad de Ronda, sobre que se tomen cuentas de los arbitrios concedidos a dicha ciudad para solar la iglesia mayor y concluir la obra del puente. 
La necesidad de disponer del nuevo paso seguía siendo apremiante. Unos años más tarde las autoridades solicitaban que se les prorrogaran los arbitrios por 7 años, a excepción del $1 \%$ de la carne pues este impuesto resultaba muy gravoso al vecindario. Así se hizo en 1733 y comenzó a aplicarse desde principios del año siguiente, cuando la obra es encomendada a Camacho. También fue destinada una parte del grano del pósito en donde a mediados de siglo eran señaladas 564 fanegas de trigo "para la obra de la puente». Todavía en 1754 era vendida cierta cantidad a $38 \mathrm{rs}$. la fanega por valor de $21.812 \mathrm{rs}^{7}$.

\section{La ruina del puente}

"Y aunque procuró esta ciudad traer en distintas ocasiones otros maestros áviles que reconocieran lo operado, en lo público decían mucha bondad de la obra pero lo cierto es que después de consumidos muchos fondos y cerrado el arco, éste se hundió con pérdida de muchas vidas». Parece ser que la ruina se debió a un equivocado proyecto, deficientes materiales y mala ejecución. Sin duda que la falta de trabajo a principios de siglo XVIII en que se prolonga la crisis de décadas anteriores empujaba a los canteros a contratar obras con presupuestos muy bajos. Esto les obligaba a trabajar con un gasto mínimo y pobres materiales, lo que traía resultados defectuosos como hemos visto que también ocurrió en la colegiata. Los ejemplos de puentes españoles de la época denunciados ante el Consejo Real por sus malos resultados fueron constantes. Otro de los motivos fue achacado a ser contratado por subasta y no a jornal, con lo que la inversión quedaba reducida al mínimo. Esto explicaría el que en la segunda mitad de siglo, cuando es levantado el actual puente nuevo, ningún maestro se ofreciera a llevarlo a cabo por contrata sino a jornal.

El más antiguo dibujo que conservamos, algo posterior a los años citados, nos muestra arriba restos de los apoyos de aquel viejo puente. Son los arranques del arco, asentados en lo alto de la roca del tajo. Sin duda que el arco proyectado llevaba una anchura excesiva para las técnicas constructivas de la época, lo que trajo su ruina y más para unos canteros formados tradicionalmente, sin los conocimientos necesarios que solo podían adquirirse con las enseñanzas regladas de las academias. Todos los arquitectos oficiales que posteriormente intervinieron en el puente redujeron el tamaño del arco (o arcos) levantando sus

7 AHN, Cons. leg. 6.118. 


E Vartar Inocencio Cadiñanos Bardeci

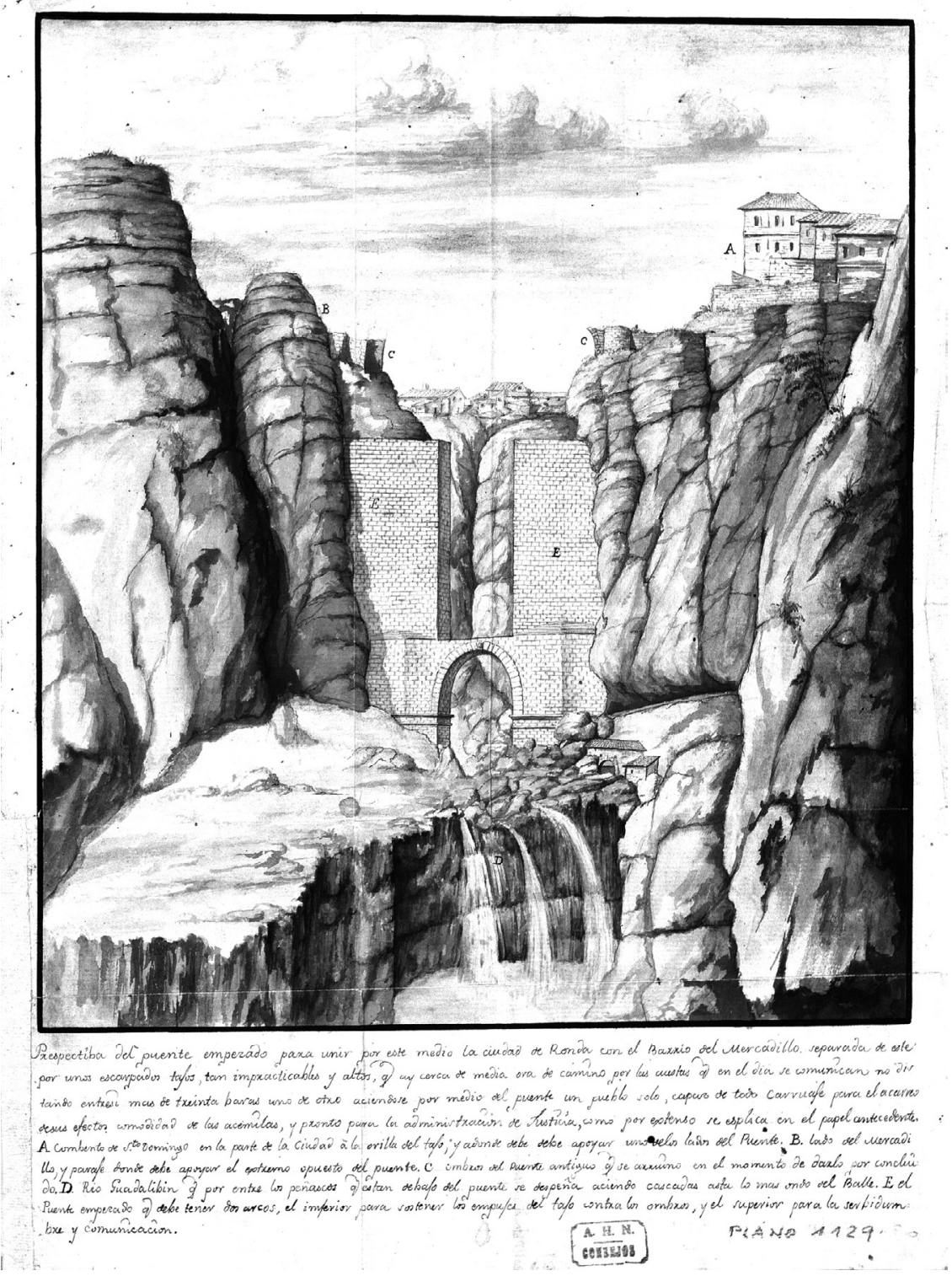

Perspectiva del puente empezado para unir por este medio la ciudad de Ronda con el barrio del Mercadillo (arriba y al fondo pueden verse los arranques de los arcos del primitivo y antiguo puente). A. Convento de Santo Domingo. B. Lado de Mercadillo. C. Hombros del puente antiguo que se arruinó en el momento de darlo por concluido. E. El puente empezado que debe de tener dos arcos, el inferior para sostener el empuje al Tajo y el superior para la servidumbre y comunicación 
pilares desde el fondo del tajo y reduciendo la luz de las roscas, lo que se mostró como la única y verdadera solución.

\section{Proyecto de un nuevo puente}

Tras la ruina "la ciudad solicitó ver si nuevamente podía volver a hacerse este arco de taxo a taxo, halló que sus cimientos y quanto había obrado el Camacho estaba con falsedad por haberlo hecho con menos costo y que le quedaran más útil en lo que desfalcaba de justificación según declaración de maestros».

Camacho presentó un memorial junto con José García Landaverde, maestro de arquitectura y director de la andamiada. Reconocieron que la obra estaba falsa por levantarse sobre las antiguas bases y apoyos de Gutiérrez. Propusieron construir un nuevo puente en sitio más seguro y de igual comodidad y con ciertas calidades y condiciones. Iría a quince varas de distancia aguas abajo, o sea, en el actual emplazamiento. Iba compuesto de dos arcos y arrancaba en el cauce del río, tal como hoy puede verse. Sería, pues, completamente nuevo sin aprovechamiento alguno de lo antiguo, a excepción de los materiales.

La ciudad acordó que fuera admitida la propuesta y así le fue comunicada al Consejo Real el 25 de julio de 1735 quien no lo aprobó hasta tanto que un perito lo reconociese e informase. Ordenó que lo viese Juan de Sobreville, ingeniero director de las obras del Campo de Gibraltar, o bien otra persona entendida. No pudo acudir Sobreville y todo quedó en suspenso por entonces.

En 1737 parecieron ante el corregidor fray Miguel de los Santos, trinitario descalzo de Málaga, maestro mayor de arquitectura y Matías de Figueroa, vecino de Sevilla, también maestro mayor de arquitectura. Vieron la propuesta de Camacho y García Landaverde. Dijeron que «han hallado se puede fabricar dicho puente por el sitio que los dichos maestros han señalado con mayor seguridad... y para la mayor decencia y capacidad de ella conviene se haga a su entrada por la parte de esta ciudad y esquina del convento de Santo Domingo que es la parte opuesta a la otra esquina donde se construyó el puente que se arruinó, se dé toda la anchura que permite el terreno y que esto mismo se ejecute a la salida de dicho puente y todo lo que permite el terreno que está en la calle de la Mina y va a desembocar a la de los Remedios del barrio de Mercadillo para quitar aquella violencia que causarían los ángulos aún para tomar la puente por las calles que la comunican y vienen transversales".

Pero todo siguió en suspenso. 
En 1756 el corregidor ordenó a los alarifes de la ciudad, Alonso Gil y Pedro de Reguera, junto con el carpintero Mateo Rodríguez y el cantero Pedro Martín Romero, que lo vieran y tasasen teniendo presentes las declaraciones anteriores. Expusieron que «hallaron tener de altura desde el río hasta el nacimiento de los arcos 53 varas, 21 varas menos del sitio por donde se arruinó. De ancho 26 varas, 18 menos que el dicho arco arruinado». Iría a 15 varas de distancia del que se había arruinado. La mayor parte del material podría sacarse del mismo sitio en que iba a fabricarse el puente. El valor y coste de las maderas para formar la cincha y espárragos que iban a salir desde el río para seguridad y firmeza de la fábrica, junto con el hierro con que se iban a ligar y sujetar los empalmes de la madera, cal, portes de la arena y otros materiales y jornales hasta enrasar el arco del puente, ascendía a 100.220 rs.

Al mismo tiempo, las autoridades insistieron en que era urgentísima la necesidad de levantar el puente pues "era general antiguo deseo de esta ciudad y sus moradores unir el barrio que llaman del Mercadillo con el casco de ella quedando comerciable y sin el fatigoso y penoso trabajo de rodeo y cuestas". Existían 21.812 rs. por la venta de 574 fanegas de trigo. El resto se pagaría de lo que se sacase de las fianzas, bienes del corregidor que lo había aprobado indebidamente y canteros que lo habían ejecutado mal, así como dinero prestado.

\section{Pleito y suspensión}

Camacho había recibido 112.109 rs. sin contar el valor de la madera y el hierro que le había entregado la ciudad. En el mencionado año constan los autos seguidos por la ciudad contra él y sus fiadores para recobrar tal cantidad. La ciudad no volvió a pensar en continuar con los antiguos proyectos ni sobre las mismas bases, ni tampoco adjudicarlo a los anteriores maestros. Lo sería por nuevas trazas y ejecutado a base de la administración de capitulares celosos del bien público.

Los cimientos del nuevo puente proyectado por M. Cayón fueron echados en 1758. También esta vez la construcción del puente nuevo iría muy lenta, con muchos problemas de financiación y sufriendo reformas y dilaciones por lo que no pudo verse concluido hasta los últimos años del siglo XVIII ${ }^{8}$.

8 CAMACHO y MIRÓ, "Antecedentes del Puente Nuevo...», p. 295. 